\title{
Could Arthropod Vectors Play a Role in the Spread of COVID-19?
}

\author{
aGeorge Poinar \\ aDepartment of Integrative Biology, Oregon State University, USA. Email: \\ poinarg@science.oregonstate.edu
}

(C) The Author 2020

Currently, the novel COVID-19 (a single stranded-RNA spherical virus in the family Coronaviridae) infects, like viral pneumonia and influenza, respiratory passages and spreads mainly by airborne infectious agents (respiratory droplets from coughs and sneezes). Virus particles (virions) also occur in the blood, intestine, and feces. While at present, there is no direct evidence that COVID-19 or any of the SARS viruses are arboviruses, what are the chances that arthropod vectors could play a role in the spread or severity of COVID-19?

While this scenario could theoretically be possible, there are several factors that would have to be overcome before it could become a reality. Due to their cosmopolitan distribution, wide host range, ability to transmit a number of different viruses from wild animals to humans and from human to human, many hematophagous arthropods [mosquitoes (Diptera: Culicidae); biting midges (Diptera: Ceratopogonidae); blackflies (Diptera: Simuliidae); sand flies (Diptera: Phlebotominae); and ticks (Acari)] are available for vectoring COVID-19, with mosquitoes being prime candidates (Fig. 1).

Before a virus can be transmitted by a bloodsucking arthropod, it must meet 2 criteria. First, the virus must occur, at least during some period during the infection, in the blood of the vertebrate host at a high enough titer to be acquired by the arthropod. Second, for biological transmission, the virus must pass through the gut wall of the vector, infect and replicate in its salivary glands to reach a high enough titer to ensure transmission to a vertebrate host (Foster $\&$ Walker, 2002). Mechanical transmission could occur if an infective dose of the virus is carried in or on the mouthparts of the bloodsucking arthropod.

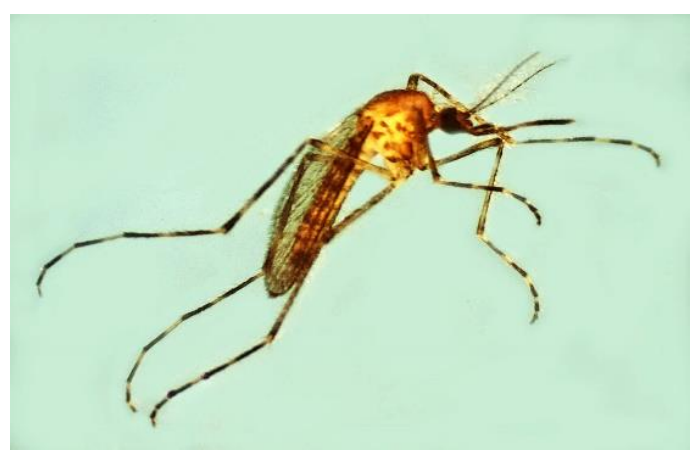

Fig. 1. A potential vector of COVID-19, this mosquito, Culex tarsalis, is now a primary vector of West Nile virus, Western Equine encephalitis virus and Saint Louis encephalitis virus, all of which infect humans (Photo by George Poinar).

Studies show that COVID-19 may spread in several ways in infected humans, including via the nose or mouth, intestine, feces, and blood (van Beusekom, 2020). In discussing a blood filter used to treat COVID-19 patients, a news release stated that "very recent publications and clinical feedback confirm the presence of the virus (RNA) in the blood of critically ill COVID -19 patients" (Balmaseda, 2020).

Coronaviruses infect a wide range of animals and in some cases, the titer of virus in blood would 
appear to be high enough to be acquired by biting arthropods. There are two feline coronaviruses that infect cats worldwide (Khan, 2005). In the feline enteric coronavirus (FEC), the virus is limited to the intestine and the virus particles are shed with the feces. Biting arthropods probably would not be able to acquire any virus particles in the blood of infected cats.

However, with the feline infectious peritonitis coronavirus, (FIPC) which is antigenically related to and serologically cross-reacts with a subgroup of mammalian coronaviruses, including the transmissible gastroenteritis of swine, human coronavirus 229-E, and canine coronavirus, cats can develop a persistent viremia (Khan, 2005). Bloodsucking arthropods would have a good chance of obtaining the FIPC virus when they feed on infected cats.

So, if the titer of COVID-19 in the blood is high enough, the first criterion would be met. The virus could be taken up by blood-sucking arthropod vectors. Still unknown is whether enough virus would replicate inside hematophagous arthropods to initiate a biological cycle. If some type of receptor cells occur in the arthropod vector, a biological cycle could be initiated. Otherwise, the transmission could be mechanical with the virus particles carried in or on the mouthparts of the potential vector.

Mosquitoes are very successful in transmitting single stranded-RNA spherical viruses of the families Flaviviridae, Togaviridae, and Bunyaviridae to humans. While these viruses cause fevers, body aches, encephalitis, nausea, vomiting, and hepatitis, they typically do not develop in the lungs of their victims as does COVID-19 (Foster \& Walker, 2002). However, some of the reservoir hosts of these arboviruses are the same as those of the COVID-19 virus (Grimley, 1991).

Since both coronaviruses and flaviviruses are abundant in bats, including insectivorous horseshoe bats of the genus Rhinolophus, which are thought to possibly be reservoir hosts of
COVID-19 (Kading \& Schountz, 2016), it could theoretically be possible for mosquitoes to acquire virions of both COVID-19 and flaviviruses when feeding on infected bats. Whether these mosquitoes could transmit COVID-19, along with flaviviruses, to both bats and humans, is unknown.

The original reservoir hosts of the deadly Yellow Fever arbovirus appear to be bats and rodents living in endemic lowland equatorial Africa and South and Central America. In its enzootic form, the virus occurs in monkeys and is spread by forest mosquitoes. In the epidemic form, it occurs in humans and is spread by mosquitoes of the genus Aedes (Foster \& Walker, 2002). When obtaining the Yellow Fever virus from bats, the mosquitoes may also be acquiring coronaviruses.

Equine encephalomyelitis is caused by arboviruses of the Togaviridae, with birds as the primary vertebrate hosts and mosquitoes as the vectors. Venezuelan equine encephalomyelitis (VEE) strain is especially interesting since horses infected with epizootic strains of VEE have a persistent and significant viremia, which could make it possible for the virus to be acquired by mosquitoes. But infections can also pass from horse to horse by respiratory secretions and direct contact. So here is a virus that has two possible methods of transmission, one by mosquitoes and the other by respiratory droplets (Khan, 2005).

Interactions between vectors and viruses are mostly unknown since the dynamics are constantly changing. Since flaviviruses and togaviruses can replicate in both insect and vertebrate hosts, they have a high capacity for rapid evolution into strains of varying virulence and host selection (Grimley, 1991). Mutations can result in a shift to new hosts as well as a change in developmental patterns in original hosts. This has been noted in the case of West Nile transmitted by Culex pipiens (Kilpatrick et al., 2008). We still don't know what mutations are possible with COVID-19. 
If tissues of the body other than the lungs and intestine become infected with COVID-19, the titer of the virus in the blood could increase, making more virions available for blood-sucking arthropods to acquire when feeding on infected humans. Blood from victims of COVID-19 that are homeless or in refugee camps could supply high levels of virus to hematophagous arthropods.

As far as known, there is no evidence that virions of COVID-19, or of any coronaviruses, are carried by hematophagous arthropods. Without some very substantial mutations, it is unlikely that the biological transmission of the virus by bloodsucking arthropods would occur. Successful transmission could theoretically be possible if the infective virus particles were physically carried on or in the mouthparts of potential vectors. Other pathogens (virus, bacteria, protozoa, etc.) introduced into patients by hematophagous arthropods could well increase the severity or delay recovery from COVID-19.

\section{References}

Balmaseda, R. (2020, March 26). ExThera's affinity blood filter is used to treat COVID-19 patients. ExThera. www.extheramedical.com

Foster, W.A., \& Walker, E.D. (2009). Mosquitoes (Culicidae). In: Mullen, G.R., Durden, L.A. (Eds.), Medical and Veterinary Entomology (2nd Ed.) (pp. 201-253). Academic Press: San Diego, CA, USA.
Grimley, P.M. (1991). Togaviridae and Flaviviridae. In J.R. Adams \& J.R. Bonami (Eds.), Atlas of Invertebrate Viruses (pp. 461-497). CRC Press: Boca Raton.

Kading, R.C., \& Schountz, T. (2016). Flavivrus infections of bats: Potential role in Zika virus ecology. The American journal of tropical medicine and hygiene, 95(5), 993-996.

https://dx.doi.org/10.4269\%2Fajtmh.16$\underline{0625}$

Kahn, C.M. (2005). The Merck Veterinary Manual ( $9^{\text {th }}$ ed.). Merck \& Co., Ltd.: Whitehouse Station, New Jersey.

Kilpatrick, A.M., Meola, M.A., Moudy, R.M., \& Kramer, L.D. (2008). Temperature, Viral Genetics, and the Transmission of West Nile Virus by Culex pipiens mosquitoes. PLoS Pathogens, 4(6), e1000092. https://dx.doi.org/10.1371\%2Fjournal.ppa t.1000092

Spielman, A., \& D’Antonio, M. (2001). Mosquito; A natural history of our most persistent and deadly foe. Faber and Faber, Limited: London, UK.

van Beusekom, M. (2020, March 12). COVID19 may spread in several different ways. CIDRAP. https://www.cidrap.umn.edu/newsperspective/2020/03/study-covid-19-mayspread-several-different-ways

Publisher's note: Eurasia Academic Publishing remains neutral with regard to jurisdictional claims in published maps and institutional affiliations.

Open Access This article is licensed under a Creative Commons Attribution-NoDerivatives 4.0 International (CC BYND 4.0) licence, which permits copy and redistribute the material in any medium or format for any purpose, even commercially. The licensor cannot revoke these freedoms as long as you follow the licence terms. Under the following terms you must give appropriate credit, provide a link to the license, and indicate if changes were made. You may do so in any reasonable manner, but not in any way that suggests the licensor endorsed you or your use. If you remix, transform, or build upon the material, you may not distribute the modified material.

To view a copy of this license, visit https://creativecommons.org/licenses/by-nd/4.0/. 